\title{
Emerging functions and clinical applications of exosomes in human oral diseases
}

\author{
Qiao Peng ${ }^{1+}$, Jing-ya Yang ${ }^{1+}$ and Gang Zhou ${ }^{1,2^{*}}$ (1)
}

\begin{abstract}
Exosomes are cell-derived membranous vesicles of endosomal origin secreted by all type of cells and present in various body fluids. Exosomes are enriched in peptides, lipids, and nucleic acids, emerging as vital modulators in intercellular communication. Exosomes are increasingly being evaluated as biomarkers for diagnosis and prognosis of diseases, because the constituents of exosomes could be reprogrammed depending on the states of diseases. These features also make exosomes a research hotspot in oral diseases in recent years. In this review, we outlined the characteristics of exosomes, focused on the differential expressions and altered biological functions of exosomes in oral diseases, including oral squamous cell carcinoma, oral leukoplakia, periodontitis, primary Sjögren's syndrome, oral lichen planus, as well as hand foot and mouth disease. Besides, accumulated evidence documents that it is implementable to consider the natural nanostructured exosomes as a new strategy for disease treatment. Herein, we highlighted the therapeutic potential of exosomes in oral tissue regeneration, oncotherapy, wound healing, and their superiority as therapeutic drug delivery vehicles.
\end{abstract}

Keywords: Exosomes, Oral disease, Oral squamous cell carcinoma, Primary Sjögren's syndrome, Periodontitis, Oral tissue regeneration

\section{Background}

It has been more than 30 years since exosomes were first described as small vesicles which were generated during the process of reticulocyte maturation and mediated the selective externalization and removal of transferrin receptor from the erythrocyte [1]. Exosomes have a characteristic lipid bilayer with an average thickness of about $5 \mathrm{~nm}$ and a cup-shaped morphology, appearing as flattened spheres with diameters ranging from 30 to $150 \mathrm{~nm}$ [2] (Fig. 1a). Exosomes are derived from almost all types of cells and present in various biological fluids, such as plasma, serum, saliva, urine and human milk [1, 3-5]. In recent years, exosomes represent a new signaling paradigm to mediate intercellular communication because of

\footnotetext{
*Correspondence: zhougang@whu.edu.cns

${ }^{\dagger}$ Qiao Peng and Jing-ya Yang contributed equally to the work

2 Department of Oral Medicine, School and Hospital of Stomatology, Wuhan University, Luoyu Road 237, Wuhan, China

Full list of author information is available at the end of the article
}

their capacity to exchange components, including proteins, nucleic acids, and lipids [6, 7] (Fig. 1b).

The critical involvement of exosomes in different types of diseases may clarify the potential mechanisms of pathological processes. At present, tumor-derived exosomes are of most interest, because of their promotion in tumor proliferation, migration and invasion ability, and their contribution to immune suppression in tumor microenvironment $[8,9]$. In addition, exosomes are reported to play a role in regulating inflammatory and immune diseases, such as rheumatoid arthritis, Sjogren's syndrome and systemic lupus erythematosus [10]. It was reported that TNF- $\alpha^{+}$exosomes promoted the $\mathrm{T}$ cell mediated pathogenesis of rheumatoid arthritis by inhibiting $\mathrm{T}$ cellactivation induced death [11]. Meanwhile, other studies focus on the potentially clinical applications of exosomes in tissue regeneration, targeted therapy, artificial exosome mimetics, or as biomarkers [12, 13]. For example, the combination of exosomes from human adipose stem cells and polydopamine-coating PLGA scaffold

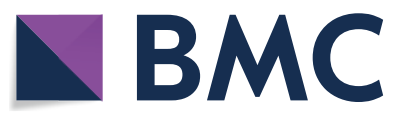

c) The Author(s) 2020. This article is licensed under a Creative Commons Attribution 4.0 International License, which permits use, sharing, adaptation, distribution and reproduction in any medium or format, as long as you give appropriate credit to the original author(s) and the source, provide a link to the Creative Commons licence, and indicate if changes were made. The images or other third party material in this article are included in the article's Creative Commons licence, unless indicated otherwise in a credit line to the material. If material is not included in the article's Creative Commons licence and your intended use is not permitted by statutory regulation or exceeds the permitted use, you will need to obtain permission directly from the copyright holder. To view a copy of this licence, visit http://creativeco mmons.org/licenses/by/4.0/. The Creative Commons Public Domain Dedication waiver (http://creativecommons.org/publicdomain/ zero/1.0/) applies to the data made available in this article, unless otherwise stated in a credit line to the data. 

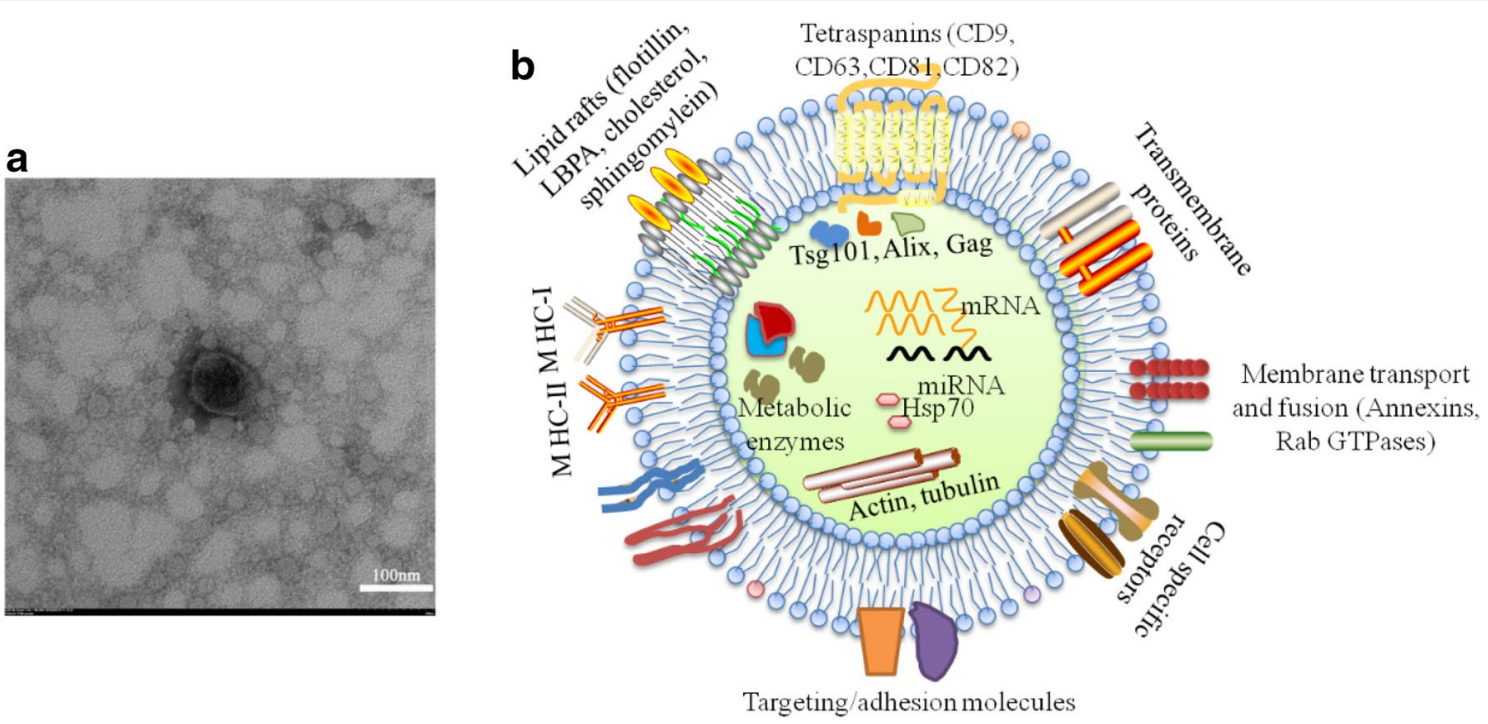

Fig. 1 Characteristics of exosomes. a electron microscopic image of exosomes. Exosome showed a characteristic lipid bilayer with an average thickness of $\sim 5 \mathrm{~nm}$ and typical cup-shaped morphology, appearing as flattened spheres with diameters ranging from 30 to $100 \mathrm{~nm}$. b Main constituent of molecules included in exosomes. Many proteins are common among all exosomes regardless of their maternal cell types, including tetraspanins, flotillin, heat shock proteins (HSP70, HSP90), MHC I, GTPases (Rab, RAL) and endosome-associated proteins (Alix, Tsg 101). Exosomes also enrich in lipid rafts on the surface, including flotillin, LBPA, cholesterol, sphingomylein, and nucleic acids in the lumen, including DNAs (mtDNA, ssDNA, dsDNA), and RNAs (mRNA, miRNA, rRNA, and tRNA)

successfully accelerated the restoration of critical-sized mouse calvarial defects [14]. Zheng et al. found that proteasome subunit alpha type 7 (PSMA7) was remarkably higher in patients with inflammatory bowel disease (IBD) than healthy controls, which indicated that exosomal PSMA7 may be a biomarker for IBD diagnosis, therefore releasing patients from the pain of colonoscopy [15].

Recent studies have revealed the multifaceted roles of exosomes in oral diseases. Oral cancer-derived exosomes exacerbated the malignancy of cancers [16-19]. Li et al. proved the hypoxic oral squamous cell carcinoma (OSCC) cells secreted miR-21-rich exosomes in a HIFdependent manner [20]. Increased exosomal miR-21 markedly enhanced the expression of snail and vimentin, but decreased E-cadherin level in OSCC cells, which ultimately contributed to the migration and invasion of OSCC cells [20]. Exosomes were also a kind of message transmitter that transmitted signals between tumor cells and other type cells. Exosomal miR-29a-3p from OSCC cells promoted M2-type macrophages polarization, and such macrophages enhanced the proliferation and migration of OSCC cells [21]. The ubiquitous existence of exosomes in human body fluids makes exosomal composition promising biomarkers for real-time monitoring in clinical application. In our previous work, circulating exosomal miRNAs were identified differentially expressed in oral lichen planus (OLP) patients. Especially, the increased expression of circulating exosomal
miR-34a-5p in OLP was positively correlated with the disease severity [22]. Of importance, in regenerative medicine, exosomes derived from oral mesenchymal stem cells (MSCs) were able to regenerate oral tissues such as dental pulp and periodontal tissues [23-26].

Based on the current knowledge, we describe the mechanisms of exosomes formation and signal transmission, and summarize the latest studies on the roles of exosomes in different oral diseases. Moreover, we emphasize the potentially clinical applications of exosomes on oral tissue regeneration, oncotherapy, wound healing, and as therapeutic drug vehicles for oral diseases.

\section{Characterization of exosomes}

Exosomes originate from an endocytic compartment. Originally, early endosome is formed by inward budding of plasma membrane. During maturation of early endosome, the inward budding of limited areas of the endosomal membrane to form intraluminal vesicles (ILVs) produces multivesicular bodies (MVBs), also known as late endosomes [27]. During the inwarding process of ILVs, many cytoplasmic components are encapsulated. Two fates have been identified for MVBs: some of them deliver to lysosomes or autophasome for degradation, while others fuse with the plasma membrane. In the former process, MVBs directly fuse with lysosomes to form autolysosome or fuse with autophasosome to form amphisome, where endocytosed cargos are degraded; 
while, in the latter process, MVBs fuse with plasma membrane inducing exosome secretion $[28,29]$. It is usually considered that exosome secretion requires formation of an endosomal sorting complex required for transport (ESCRT) machinery [22].

Evidence demonstrated that exosomes were closely associated with cell proliferation, apoptosis, antigen presentation, immune regulation, tissue regeneration and tumor initiation [30-32]. How exosomes transmit the signals into incorporating cells is still an unresolved question, but three potential mechanisms have been demonstrated (Fig. 2): (1) exosomes are endocytosed/ internalized and then fuse with the endosomal limiting membrane of recipient cells; (2) exosomal membranes directly fuse with the plasma membrane of recipient cell; (3) exosomes attach to recipient cell surface by receptor-ligand interaction [33, 34]. After reception, it is the diverse biological composition within the exosomes, including proteins, lipids and nucleic acid that functions in exosomes mediate intercellular signaling transmission, which play key roles in maintaining homeostasis and regulating the physiopathological processes $[35,36]$.

\section{Exosomes in oral diseases}

Exosomes in oral squamous cell carcinoma

Oral squamous cell carcinoma (OSCC) is the most common epithelial cancer of the head and neck [37, 38 ]. OSCC is highly malignant and prone to local invasion and cervical lymph node metastasis, causing facial deformity, speech and esthetic disorders and leading to low survival rate and poor quality of life [38].

\section{Proteins in OSCC cell-derived exosomes}

Exosomal proteins can promote tumor development in both paracrine and autocrine ways. Exosomes containing EGFR from OSCC cells were capable of transforming normal epithelial cells into a mesenchymal phenotype in a paracrine fashion [17]. Hou et al. found that exosomes from salivary adenoid cystic carcinoma cell line SACC-83 enhanced the migration and invasion ability of the parental SACC-83 by targeting cell junction-associated proteins, including claudin-1, ZO-1, and $\beta$-catenin $[16,39]$.

The protein composition in OSCC cell-derived exosomes (OSCC-Exos) could be changed significantly after ionizing radiation $[40,41]$. This alteration reinforced the exosome secretion, the survival of irradiated OSCC

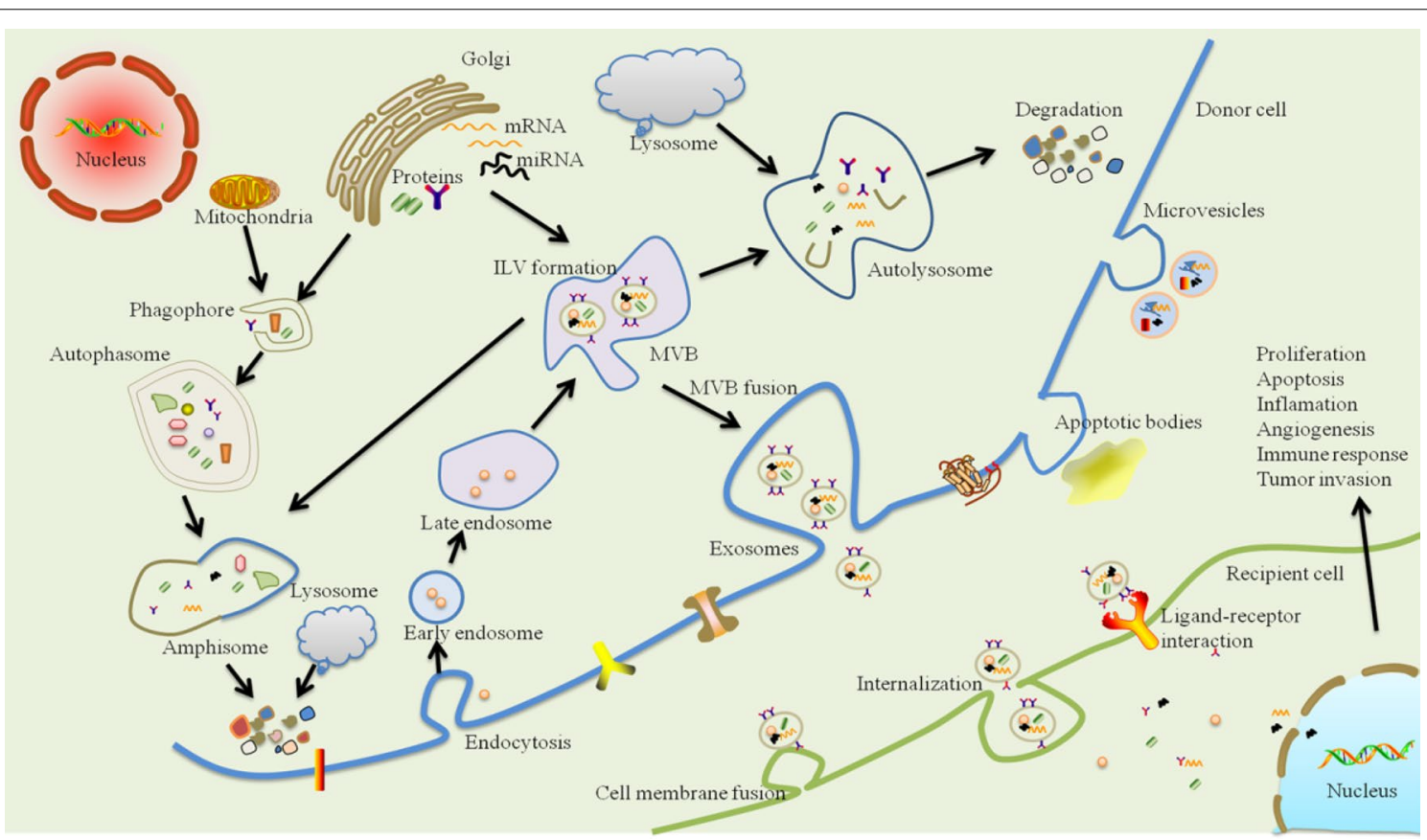

Fig. 2 Schematic representation of exosome biogenesis, release and intercellular communication. Exosomes originate from an endocytic compartment. Early endosome is formed by the inward budding of plasma membrane. During maturation of early endosome, the inward budding of limited areas of the endosomal membrane to form intraluminal vesicles (ILVs) produces multivesicular bodies (MVBs). MVBs faced two fates, where some of them are delivered to lysosomes or autophasome for degradation, while others fuse with the plasma membrane inducing the secretion of exosomes. During the inwarding process of ILVs, many cytoplasmic components are encapsulated, such as proteins, lipids and nucleic materials, which makes them represent a new signaling paradigm to interfere cell-to-cell communication. Moreover, this intercellular signal transmission might be mediated through three pathways, including endocytosis/internalizatioin, direct membrane fusion, or receptor-ligand interaction 
cells, and the proliferation of non-irradiated OSCC cells, because exosomes were able to repair the broken DNAdouble strand [40]. Furthermore, differential expression patterns of protein in OSCC-Exos probably reflected the states of disease. Ono et al. revealed that exosomes secreted by metastatic phenotype of OSCC cells comprised larger amount of oncogenic proteins, including EpCAM, EGFR, and HSP90 than their parental OSCC cells. In addition, highly expressed HSP90, TRAP1 and HSP105 were correlated with poor prognosis of OSCC and thus could be potential prognostic biomarkers for OSCC [42].

Moreover, OSCC-Exos internalized by NK cells could up-regulated the expression of interferon regulatory factor 3 (IRF-3) and its phosphorylation by releasing NF-kBactivating kinase-associated protein 1 into NK cells [43]. Overexpressed IRF-3 drove NK cells to express type I interferon, chemokine and costimulatory molecules, hence enhancing their tumor-suppressing functions, including cell proliferation, release of perforin and granzyme $\mathrm{M}$, and cytotoxicity toward tumor cells [43].

\section{MiRNAs in OSCC cell-derived exosomes}

Hypoxia is a common feature of OSCC and associated with aggressiveness and poor outcomes [44]. Li et al. found that exosomes purified from supernatants of hypoxic OSCC cell lines SCC-9 and CAL-27 significantly overexpressed miR-21 in a HIF-1a and HIF-2a-dependent manner, which promoted the migration and invasion of OSCC cells in vitro and induced tumor growth and metastasis in xenograft mice model [20]. Interestingly, exosomes derived from cisplatin-resistant OSCC cells could transfer miR-21 into their OSCC parental cells [18]. This transference of miR-21 exerted an enhancement effect on chemoresistance and decreased the DNA damage signaling in response to cisplatin by targeting phosphatase and tensin homolog and programmed cell death 4 [18]. Therefore, hypoxia and cisplatin treatment may simultaneously stimulate tumor cells to generate miR-21-rich exosomes, which in turn reinforce the prometastatic behaviors and the resistance to chemotherapy, respectively.

Sakha et al. identified that exosomes secreted from highly metastatic human oral cancer cell line HOC313LM (HOC313-LM-Exo) could induce cell growth via activating the ERK and AKT pathways. HOC313-LMExo expressed highly amount of miR-342-3p and miR1246, enhancing the cell motility of its parental cell line HOC313 and the establishment of the metastatic niche by communication between cancer cells and normal cells. Exosomal miR-1246, in particular, was significantly associated with the malignancy by directly targeting DENN/ MADD Domain Containing 2D [19].
OSCC cell-derived exosomal miRNAs can exacerbate the severity of disease not only by functioning on the OSCC cells itself, but also by boosting the M2-polarization of macrophages. Macrophages are documented to play critical roles in the tumor microenvironment. With the induction of tumor cells they can differentiate into tumor-associated macrophages (TAM), which is similar to M2-like phenotype polarization, showing great diversity and plasticity [45]. We have previously identified that the expression of $\mathrm{CD}_{163}{ }^{+}$macrophages (M2 macrophages) was higher in oral leukoplakia (OLK) and OSCC than that in normal oral mucosa $[46,47]$. Others also proved a marked positive correlation between the increased $\mathrm{CD} 163^{+}$macrophages and the pathological grade of OSCC [48], supporting the importance of M2 macrophages in the progression of OLK and OSCC. Recently, a report found the positive participation of OSCC-Exos in M2-subtype macrophages polarization [21]. This M2 polarization was induced by highlyexpressed miR-29a-3p in OSCC-Exos, which negatively regulated the activity of SOCS1/STAT6 signaling pathway, aggravating the proliferation and invasion of SCC9 and CAL-27 [21].

\section{Carcinoma associated-fibroblast-derived exosomes}

Carcinoma associated-fibroblasts (CAFs) are a highly enriched cellular stromal component of many solid tumors $[49,50]$. By secreting diverse cytokines, growth factors and chemokines, CAFs enhanced the drug-resistance acquisition, induced the EMT, and contributed to the progression, invasion, metastasis, and angiogenesis of cancer cells [51]. Recently, extracellular vesicles were reported to play a central role in the crosstalk between tumor cells and CAFs [52-55].

Jiang et al. showed that normal human gingival fibroblasts exhibited a phenotype switch to CAFs after coculture with CAL-27-derived microvesicles [55]. The microvesicle-activated CAFs in turn promoted the migration and invasion of OSCC cells via producing more lactate [55]. In addition, exosomal miR-155 derived from melanoma cells upregulated the expression of proangiogenic factors, such as VEGF, FGF2, MMP9, in CAFs by targeting SOCS1/JAK2/STAT3 signaling pathway, which resulted in the increase of melanoma angiogenesis [56].

On the other hand, CAF-derived exosomes modified the metabolic reprogramming of cancer cells, and upregulated the expression of invasion-associated genes, such as ROCK2, FLOT1 and FAM129B [54]. Li et al. found that the expression of miR-34a-5p in CAF-derived exosomes was significantly reduced, while overexpression of exosomal miR-34a-5p could inhibit the tumorigenesis of OSCC [53]. After binding with its direct downstream target AXL, miR-34a-5p strengthened 
OSCC malignancy through directly targeting the AKT/ GSK-3 $\beta / \beta$-catenin/Snail signaling pathway [53]. Besides, Languino et al. proved that, in OSCC, CAF-derived exosomes could stimulate the TGF- $\beta$ signaling pathway in keratinocytes by exosomal T $\beta$ RII [52], which enhanced the possibility that TGF- $\beta$ signaling might be influenced by intercellular communication between tumor and the microenvironment.

\section{Body fluids-derived exosomes in OSCC}

Liquid biopsy has been extensively investigated in recent years because of obvious advantages, such as its minimal invasiveness, painlessness, inexpensiveness, and repeatability [57]. Since biological cargos of exosomes from various physiological fluids changed greatly depending on different stages and types of diseases, it is of great potential to exploit exosomal cargos as biomarkers in the field of liquid biopsy.

\section{Salivary exosomes in OSCC}

Zlotogorski-Hurvitz et al. identified that the size and concentration of OSCC-Exos from oral fluid were larger and higher than that of healthy individuals and the expression of CD81 was significantly lower in OSCC [58]. Gai et al. revealed an upregulation of miR-412-3p, miR512-3p, miR-27a-3p, miR-373-3p and miR-494-3p in salivary exosomes from OSCC patients [59]; furthermore, miR-302b-3p and miR-517b-3p were expressed specifically only in samples from OSCC group [59].

In addition, proteome analysis showed that salivary exosomes isolated from OSCC patients were enriched in proteins related to the inflammatory system, transport of metals, as well as cellular growth and proliferation [60]. These functional biomolecules within the salivary exosomes were able to induce inflammatory cells migrate to the tumor sites through chemotactic mechanisms, which may be important in the subsequent immunoediting of inflammatory cells [60].

Fourier-transform infrared (FTIR)-based spectrum of salivary exosomes could differentiate OSCC from healthy individuals with a sensitivity of $100 \%$ and specificity of $89 \%$, displaying a specific mid-infrared spectral signature for OC salivary exosomes [61]. This difference was caused by the subtle changes of exosomal proteins, lipids and nucleic acids in salivary from patients with OSCC [61].

\section{Circulating exosomes in OSCC}

It was reported that plasma exosomes from OSCC exerted suppressive effects on immune system by downregulating the expression of NKG2D in NK cells [62]. In patients with active disease, plasma exosomes were more effective to establish an immune suppressive microenvironment by increasing the apoptosis of $\mathrm{CD} 8^{+}$ $\mathrm{T}$ cells, inhibiting the proliferation of $\mathrm{CD} 4^{+} \mathrm{T}$ cells, and promoting the production of Treg cells [62]. These findings indicated that circulating exosomes from OSCC may contribute to the development of OSCC by suppressing the anti-cancer effects of NK cells and T cells.

In addition to affecting the anti-cancer immunity, circulating exosomes also displayed a tight connection with OSCC status. Compared to plasma free miRNAs, the expression profiles of plasma exosomal miRNAs from tongue SCC patients more resembled the tumor tissues [63]. Similarly, the level of PD-L1 carried by plasma exosomes instead of soluble PD-L1 level was correlated with disease severity, the UICC stage and the lymph node status [64]. Moreover, Wang et al. have identified a higher expression of laminin-332 in plasma exosomes from OSCC patients with lymph node metastasis [65]. Li et al. found that serum exosomal miR-21 level was closely associated with HIF-1a/HIF-2a expression, $\mathrm{T}$ stage, and lymph node metastasis [20]. Therefore, cargos in circulating exosomes were of potentiality to be used as novel diagnostic biomarkers for the surveillance of tumor conditions and lymph node metastasis in OSCC.

\section{Exosomes in oral leukoplakia}

Oral leukoplakia (OLK) refers to a white patch or plaque of the oral mucosa that cannot be defined as a known disease or disorder and carries an increased risk of progressing to OSCC [66]. OLK is one of the most common oral premalignant disorders (OPMD) with malignant transformation rates of $2 \%$ to $5 \%$ [67].

A newly published study reported that exosomal miR8485 secreted by MSCs derived from OLK with dysplasia played a promoting role in the proliferation, migration and invasion of DOK and SCC-15 cell lines [68]. Another research demonstrated that in hamster OPMD model, bone marrow-MSCs-derived extracellular vesicles with genetically modified overexpression of miR-185 (MSCEV-miR-185) were capable of remarkably attenuating inflammation severity and decreasing degree of dysplasia in the OPMD tissue [69].The MSC-EV-miR-185 treatment obviously reduced the expression of proliferation marker PCNA and angiogenic marker CD31, and induced cell apoptosis in the buccal lesions, indicating their potential value as a novel therapeutic option for OPMD [69].

\section{Exosomes in periodontitis}

Periodontitis is a chronic multifactorial inflammatory disease of supporting tooth structures initiated by dysbiotic plaque biofilms [70,71]. It is primarily characterized by the loss of periodontal tissue support including clinical attachment loss, alveolar bone destruction, presence 
of periodontal pocketing and gingival bleeding, irreversibly impairing the integrity of the periodontium and finally leading to tooth loss [72, 73].

Periodontal ligament fibroblasts (PDLFs) are the main cell populations that contact pathogenic microorganisms in early periodontal inflammation [74]. After lipopolysaccharide (LPS) stimuli, human PDLF-derived exosomes slightly upregulated the expression of IL- 6 and TNF- $\alpha$ in osteoblasts, and concomitantly significantly inhibited the expression of osteogenesis-related elememts, including collagen-I and osteoprotegerin, and reduced the activity of alkaline phosphatase [75]. PDLFs also engage in the maintenance of periodontal tissue homeostasis in the oral mechanical environment [76]. Stimulated with cyclic stretch, PDLFs secreted exosomes that could suppress IL- $1 \beta$ production in LPS-treated macrophages through the inhibition of NF- $\mathrm{kB}$ signaling pathway [77].

Periodontal ligament stem cells (PDLSCs) is a unique MSC population that displays self-renewal ability and multipotency when interacts with their surrounding inflammatory microenvironment [78]. Compared with exosomes extracted from normal PDLSCs, exosomes derived from LPS-stimulated PDLSCs contained a higher amount of miR-155 and its downstream target Sirtuin-1, which reduced the expression of Th17 but increased the expression of Treg, thereby alleviating the inflammation through the Th17/Treg/miR-155-5p/Sirtuin-1 regulatory network [79].

In salivary, the level of exosomal PD-L1 mRNA was higher in periodontitis than controls, and high expressions of PD-L1 were associated with advanced stages of periodontitis [80]. On the contrary, the level of salivary CD9 and CD81 exosomes was reduced in periodontitis and negatively correlated with disease status $[79,81]$.

\section{Exosomes in primary Sjögren's syndrome}

Primary Sjögren's syndrome (pSS) is a chronic autoimmune disorder characterized by focal lymphocytic infiltration of the exocrine glands, such as salivary gland and lacrimal gland, mostly leading to dry eyes and dry mouth $[82,83]$. Although the exact etiology and pathogens still remain unclear, evidence imply the critical role of exosomes in the dysregulation of immune system in pSS.

In pSS, salivary gland epithelial cells (SGECs), one main source to secrete autoantigens such as Ro/SSA and $\mathrm{La} / \mathrm{SSB}$, played a pivotal role in the initiation and progression of pSS in the local immune response [84, 85]. Recently, SGECs was reported to secreted exosomes that were highly contained autoantigens of Ro/SSA, La/SSB and $\mathrm{Sm}$, demonstrating a novel mechanism of autoantigen presentation causing the autoimmune response [86]. In addition, Aqrawi et al. identified novel potential biomarkers of APMAP, GNA13, WDR1 in saliva-derived exosomes and APEX1, PRDX3, CPNE1 in tear-derived exosomes from pSS that may be used as an additional diagnostic process to increase diagnostic accuracy [87].

Epstein-Barr virus (EBV) was considered as another important factor contributing to the pathogenesis of pSS because of its tropism for salivary glands and the ability to preferentially infect B cells [88]. Gallo et al. showed that exosomal ebv-miR-BART13-3p derived from EBVinfected B cells was functionally transferred into SGECs [89]. The exosomal ebv-miR-BART13-3p directly targeted stromal interacting molecule 1 (STM1) in SGECs, and then resulted in loss of store operated $\mathrm{Ca}_{2}{ }^{+}$entry and $\mathrm{Ca}^{+}$-dependent activation of nuclear factor of activated $\mathrm{T}$ cells, leading to the salivary dysfunction in pSS [89].

\section{Exosomes in oral lichen planus}

Oral lichen planus (OLP) is a common inflammatory autoimmune disease involving oral mucosa with unclarified etiology [90]. Clinically, OLP usually presents as symmetrical, bilateral or multiple lesions with 6 different clinic patterns of reticular, papular, plaque, erosive, bullous, and atrophic [91]. Pathogenesis of OLP has not been completely elucidated yet. However, $\mathrm{T}$ cell-mediated antigen-specific mechanism was found to play a key role in the pathogenesis of OLP, which leaded to the disruption of basement membrane by inducing the apoptosis of keratinocytes [92].

Recent studies indicated that the aberrant expression of exosomal miRNAs might participate in the development of OLP. J-S Byun et al. reported that exosomal miR-4484 from salivary was increased in patients with OLP [93]. Our group showed that plasma-derived exosomal miR$34 a-5 p$ and miR-130b-3p were significantly upregulated while exosomal miR-301b-3p was downregulated in OLP, and a positive correlation was found between expression of exosomal miR-34a-5p and the severity of OLP [22]. We also found that circulating exosomes from OLP, especially the erosive type, could significantly enhance $T$ cell proliferation and attenuate the apoptosis, and remarkably increase the migration capacity of $\mathrm{T}$ cells as well as the ratio of IFN- $\gamma / \mathrm{IL}-4$, potentially accelerating the OLP progression by regulating the $\mathrm{T}$ cell-mediated inflammatory response [94].

\section{Exosomes in hand, foot and mouth disease}

Hand, foot, and mouth disease (HFMD) is a worldwide epidemic acute viral illness, in which two major causative agents human enterovirus 71 (EV71) and coxsackievirus A16 (CVA16) account for more than $70 \%$ of cases in recent outbreaks $[95,96]$. The extremely severe HFMD 
(ESHFMD) mainly caused by EV71 has severe neurologic clinical symptoms and significant fatalities [97].

Jia et al. validated three significantly differential expressed serum exosomal miRNAs (miR-671-5p, miR16-5p and miR-150-5p) between children with HFMD and healthy controls, where exosomal miR-671-5p and miR-150-5p were decreased while exosomal miR-16-5p was increased in patients with a specificity of $72-100 \%$ and sensitivity of $78-100 \%$ [98]. In addition, significant difference was also identified among the three exosomal miRNAs between mild HFMD and ESHFMD, where miR-671-5p was only detectable in healthy and mild HFMD, providing supplemental biomarkers for subtyping HFMD infections [98] (Table 1).

\section{Present and future prospects of exosomes on oral treatments}

Therapeutic potential of mesenchymal stem cell-derived exosomes

Mesenchymal stem cells (MSCs) are progenitor cells with differential potential and self-renewable capacity [99], originally isolated from bone marrow and subsequently from other tissues [100]. In addition to the wellknown bone marrow-derived MSCs (BM-MSCs) and adipose-derived stem cells (ADSCs), in the field of dental research, several types of dental stem cells isolated from mature and immature teeth, such as dental pulp stem cells (DP-MSCs), stem cells derived from dental pulp of human exfoliated deciduous teeth (SHEDs) and periodontal ligament stem cells (PDLSCs), are attracting more and more attention [99].

Notably, in the latest studies, MSCs-derived exosomes are increasingly recognized as promising strategies to alleviate tissue injury and promote tissue regeneration in dental treatment, including dental pulp regeneration, oral oncotherapy and periodontal regeneration.

\section{Exosomes and dental pulp regeneration}

Huang et al. showed that exosomes derived from DPMSCs (DP-MSCs-Exos) cultured under odontogenic differentiation conditions triggered dental pulp-like tissue regeneration, such as increased expression of DMP1, DPP and active blood vessels in a tooth root-slice model [101]. Normally, dental pulp is highly vascularized which is fundamental to nutrient supply, waste removal and anti-inflammatory response [102]. It was reported that dental pulp cells-derived exosomes contributed to the vascularization via promoting the proliferation, proangiogenic factor expression (VEGF-A, MMP-9, FGF2 , KDR), and tube formation of human umbilical vein endothelial cells [103].

In addition, the tooth development was modulated by interaction between the epithelial cells and mesenchymal cells, and exosomes was critical in this process. Exosomes derived from epithelial cells promote mesenchymal cells to produce dentin sialoprotein and undergo mineralization while exosomes secreted by mesenchymal cells escalated the expression of basement membrane components, ameloblastin and amelogenenin in epithelial cells [104]. Moreover, it is worth noting that schwann cells, the principal glial cells in peripheral nervous system, played an important immunomodulatory role in dentin repair. Exosomes from schwann cells accelerated the proliferation and matained the multipotency and self-renewal capacities of dental pulp cells through upregulation of Oct4, Sox 2 and Nanog, providing great application potential in tissue regeneration [105].

To be brief, exosomes may lead to dental pulp regeneration via increasing the expression of specific proteins, promoting the vascularization, modulating the interaction between epithelial and mesenchymal cells, and augmenting the abilities of dental pulp cells, which might serve as an important therapeutic method in the future.

\section{Exosomes and oncotherapy}

In 2016, Altanerova et al. demonstrated that DP-MSCExos may inhibit tumor through its dual tumor cell killing activity. For one thing, exosomes released from DP-MSCs that transduced with yCD::UPRT mRNA (yCD::UPRTDP-MSCs-Exos), a suicide gene, could be internalized by tumor cells and allow tumor cells to translate nontoxic 5-FC to toxic 5-FU, leading to cancer cell death in a dose-dependent manner in the presence of a prodrug 5-fluorocytosine [24]. For another, the yCD::UPRT-DPMSCs-Exos labeled with iron oxide (Venofer) behaved as magnetic nanoparticles, which were more effective at inducing tumor cell death by alternating magnetic fieldinduced intracellular hyperthermia and/or by exposure to the prodrug 5-FC [24, 67]. Moreover, exosomes derived from menstrual mesenchymal stem cells (MenSC-Exos) exerted an antitumor effect by decreasing the angiogenesis in OSCC model [106].

Besides, exosomes derived from SHEDs (SHEDsExos) displayed potent anti-inflammatory properties by suppressing edema, cathepsin B and MMPs induced by carrageenan in mice [107]. Under oxidative stress conditions, SHEDs-Exos was reported to show neuroprotective abilities via inhibiting the apoptosis of dopaminergic neurons [108].

\section{Exosomes and periodontal regeneration}

It was found that MSCs mediated periodontal regeneration through secretion of exosomes. In rats with periodontal intrabony deficiencies, collagen sponges that contained human MSCs-Exos could more efficiently repair the defects than control rats with newly-formed 


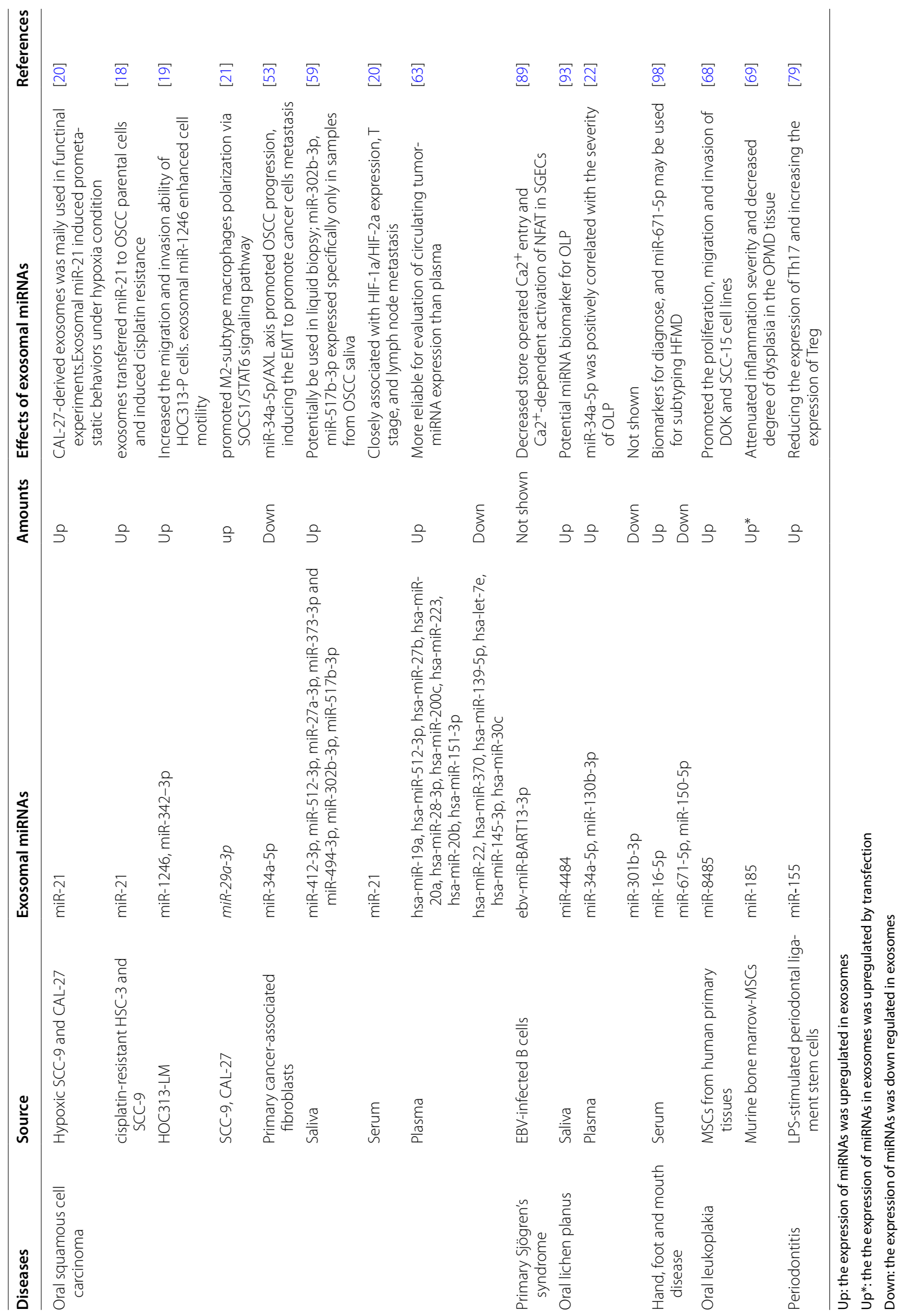


bone and PDL, and concomitantly lead to the proliferation of $\mathrm{PCNA}^{+}$cells [25]. The followed experiments performed in PDL cells proved that, human MSCs-Exos could be rapidly taken up by PDL cells and promoted the migration and proliferation of PDL cells through CD73mediated adenosine receptor activation of AKT and ERK signaling pathways [25]. Researchers also observed that exosomes secreted by adipose-derived stem cells (ASCsExos), exerted a better therapeutic effect on ligatureinduced periodontitis compared to ADSCs themselves, which manifested as a higher area of newly formed tissues [109].

\section{Wound healing efficiency of exosomes}

The oral mucosa displays unique regenerative properties such as foetal-like wound healing and antibacterial properties [110, 111]. On contrary to the "reparation" of skin wounds that heal with scar, the "regeneration" of wounds in the oral mucosa tends to heal without scar [112]. Therefore, sheets of oral mucosal epithelial cells (OMECs) are currently used after endoscopic removal of superficial tumours in the esophagus to alleviate esophageal stricture and improve mucosal healing.

The latest research showed that, exosomes isolated from conditioned media of human OMECs sheets exhibited pro-regenerative effects on skin wound healing [26]. These exosomes attenuated the proliferation of human skin fibroblasts in a dose-dependent manner and considerably increase the gene expression of growth factor HGF, VEGFA, FGF2 and CTGF in vivo, and significantly reduced the wound size in rat models in vitro [26]. These findings revealed the clinical application potential of combining cell sheets with exosomes in the future treatment of patients with early esophageal cancer.

\section{Application of exosomes as therapeutic drug delivery vehicles}

Although chemotherapy have already exhibited excellent therapeutic effects on OSCC treatment at present, it often shows severe side effects. In recent years, nanodrug delivery system have emerged as a key advance in cancer treatment for its multiple advantages than traditional drugs, including diminished drug degradation, increased targeting efficiency and prolonged drug release [113]. Notably, exosomes derived from different cells with specific cell tropism and enhanced ability to target specific tissues or organs are newly recognized natural nanocarriers $[114,115]$. Besides, it seems more easier for exosomes to escape phagocytosis by the mononuclear phagocyte system than the synthetic nanodrugs, making them function as an "invisibility cloak" for incorporated therapeutic agents [116].
Signal regulatory protein $\alpha$ (SIRP $\alpha)$, a cell-surface protein mainly expressed on macrophages and dendritic cells, could bind to CD47 [117]. In our previous study, we identified that CD47 was overexpressed in OSCC lesions and cell lines, and the CD47-SIRP- $\alpha$ interaction inhibited the engulfment of tumor cells by macrophages and promoted M2 macrophages differentiation, mediating the anti-phagocytosis and immune escape of OSCC cells $[46,47]$. Accordingly, Koh et al. established a type of exosomes engineered with SIRP $\alpha$ variants (SIRP $\alpha-$ exosomes) [118]. The SIRP $\alpha$-exosomes significantly increased the phagocytic capacity of macrophage, attenuated tumor growth. Moreover, the SIRP $\alpha$-exosome based platform remarkably augmented $\mathrm{T}$ cell infiltration in syngeneic mouse models of cancer [118]. It is plausible to speculate that exosomes equipped with specific antagonists, an emerging strategy for nano-immuno cancer therapy, may be promising for tumor treatment in the future.

Paclitaxel, performing best to induce the apoptosis of OSCC cells (40-50\%) in comparison with daunarubicin, doxorubicin and vincristine, and exhibiting a highest negative correlation with multiple drug resistance (MDR)-linked gene expression, may be the best choice of treatment for the studied OSCC patients [119]. Kim et al. showed that the incorporation of paclitaxel into exosomes significantly augmented paclitaxel accumulation in drug-resistant lung cancer cells and was 50 times more cytotoxic than conventional paclitaxel in vitro [116]. All the results imply the superior inhibition of exosomes carrying paclitaxel on OSCC cells and merit further exploration and confirmation.

Efforts to develop RNA interference therapeutic technology have been significantly intensified for biomedical application. Delivering short interfering RNA (siRNA) to recipient cells is an effective method to selectively suppress target mRNA of interest, showing great potential for use in disease treatment [120]. However, naked siRNA is rapidly degraded by nucleases in the blood circulation and might fail to pass into target cell membranes due to their negatively charged surface $[121,122]$. Encapsulation of siRNAs in exosomes is a promising novel strategy to overcome most of these delivery issues. It is noteworthy that DNA damagerelated response plays a central role in maintaining genomic stability and cellular survival. RAD51, as a DNA repair gene, is involved in DNA damage response, cell cycle checkpoint and maintains the stability of the gene [123, 124]. Overexpression of RAD51 was documented in diverse human tumors, and was predicted significantly related to OSCC prognosis [125]. Shtam et al. have successfully transfected two different siRNAs against RAD51 and RAD52 into exosomes [121]. 
They proved that exosome-delivered RAD51 siRNA functionally inhibited RAD51 expression in tumor cells, induced the accumulation of cells in $\mathrm{S}$ and $\mathrm{G} 2 / \mathrm{M}$ phases, and then caused massive reproductive cell death [121]. Similarly, encapsulation of RAD51 siRNA into exosome is of great potential to improve OSCC therapeutic efficiency.

\section{Conclusions}

Growing evidence suggests that exosomes act as an important regulator in oral diseases. Exosomes derived from OSCC cells and body fluids function as key promoters in the angiogenesis, invasion, migration and metastasis of OSCC, which is a research focus all along. In recent years, the effects of exosomes on other oral diseases such as periodontitis and oral lichen planus are also receiving attentions, providing us with a more comprehensive understanding about the roles that exosomes play in oral diseases. Moreover, exosomes containing multiple biological molecules display great potential to be exploited to assist clinical diagnosis and evaluate prognosis. Exosomes-based therapies are promising strategies in oral tissue regeneration, cancer treatment, and as drug delivery vehicles in the coming future. However, researches are still largely limited at present. Future studies should not only investigate the biological functions and precise molecular mechanisms of exosomes in oral diseases, but also address the clinical applications of exosomes to facilitate the clinical translation.

\begin{abstract}
Abbreviations
ASCs: Adipose-derived stem cells; CAFs: Carcinoma associated-fibroblasts; DP-MSCs: Dental pulp stem cells; EBV: Epstein-Barr virus; ESCRT: Endosomal sorting complex required for transport; ESHFMD: Extremely severe Hand, foot, and mouth disease; HFMD: Hand, foot, and mouth disease; IBD: Inflammatory bowel disease; ILVs: Intraluminal vesicles; LPS: Lipopolysaccharide; MDR: Multiple drug resistance; MSCs: Mesenchymal stem cells; BM-MSCs: Bone marrow-derived MSCs: MVBs: Multivesicular bodies; OLP: Oral lichen planus; OPMD: Oral premalignant disorders; OMECs: Oral mucosal epithelial cells; OSCC: Oral squamous cell carcinoma; OSCC-Exos: OSCC cell-derived exosomes; OLK: Oral leukoplakia; PDLFs: Periodontal ligament fibroblasts; PDLSCs: Periodontal ligament stem cells; pSS: Primary Sjögren's syndrome; SGECs: Salivary gland epithelial cells; SHEDs: Stem cells derived from dental pulp of human exfoliated deciduous teeth; SIRPa: Signal regulatory protein a; TAM: Tumor-associated macrophages.
\end{abstract}

\section{Acknowledgements}

This work was supported by Grants from the National Natural Science Foundation of China (Nos. 81771080, 81970949, 81371147) and State Key Laboratory of Oral Diseases (SKLOD) Open Fund (SKLOD2020OF01) to Gang Zhou.

\section{Authors' contributions}

QP drafted the first version and drew figures of this manuscript. JYY revised this manuscript and make tables. QP and JYY retrieved literatures together and contributed equally to the manuscript. JZ and GZ reviewed and gave advice to the final version of this manuscript. All authors read and approved the final manuscript.

\section{Funding}

Grants from National Natural Science Foundation of China Nos. 81771080 , 81970949 and 81371147 , State Key Laboratory of Oral Diseases (SKLOD) Open Fund (SKLOD2020OF01) to Gang Zhou.

\section{Availability of data and materials}

Not applicable.

\section{Ethics approval and consent to participate}

Not applicable.

\section{Consent for publication}

Not applicable.

\section{Competing interests}

The authors declare that they have no competing interests.

\section{Author details}

${ }^{1}$ The State Key Laboratory Breeding Base of Basic Science of Stomatology (Hubei-MOST) and Key Laboratory of Oral Biomedicine Ministry of Education, School and Hospital of Stomatology, Wuhan University, Wuhan, China. ${ }^{2}$ Department of Oral Medicine, School and Hospital of Stomatology, Wuhan University, Luoyu Road 237, Wuhan, China.

Received: 22 January 2020 Accepted: 25 April 2020

Published online: 24 May 2020

\section{References}

1. Kourembanas S. Exosomes: vehicles of intercellular signaling, biomarkers, and vectors of cell therapy. Annu Rev Physiol. 2015;77:13-27.

2. Miranda KC, Bond DT, Levin JZ, Adiconis X, Sivachenko A, Russ C, et al. Massively parallel sequencing of human urinary exosome/microvesicle RNA reveals a predominance of non-coding RNA. PLOS ONE. 2014;9(5):e96094.

3. Greening DW, Gopal SK, Xu R, Simpson RJ, Chen W. Exosomes and their roles in immune regulation and cancer. Semin Cell Dev Biol. 2015:40:72-81.

4. Ibrahim A, Marban E. Exosomes: fundamental biology and roles in cardiovascular physiology. Annu Rev Physiol. 2016;78:67-83.

5. Beltrami C, Besnier M, Shantikumar S, Shearn Al, Rajakaruna C, Laftah A, et al. Human pericardial fluid contains exosomes enriched with cardiovascular-expressed microRNAs and promotes therapeutic angiogenesis. Mol Ther. 2017;25(3):679-93.

6. Edgar JR. Q\&A: what are exosomes, exactly? BMC Biol. 2016;14(1):46-52.

7. Wang Z, Chen JQ, Liu JL, Tian L. Exosomes in tumor microenvironment: novel transporters and biomarkers. J Transl Med. 2016;14(1):297-305.

8. Wan M, Ning B, Spiegel S, Lyon CJ, Hu TY. Tumor-derived exosomes (TDEs): how to avoid the sting in the tail. Med Res Rev. 2019:40(1):385-412.

9. Rao Q, Zuo B, Lu Z, Gao X, You A, Wu C, et al. Tumor-derived exosomes elicit tumor suppression in murine hepatocellular carcinoma models and humans in vitro. Hepatology. 2016;64(2):456-72.

10. Tan L, Wu H, Liu Y, Zhao M, Li D, Lu Q. Recent advances of exosomes in immune modulation and autoimmune diseases. Autoimmunity. 2016:49(6):357-65.

11. Zhang HG, Liu C, Su K, Yu S, Zhang L, Zhang S, et al. A membrane form of TNF-alpha presented by exosomes delays $T$ cell activation-induced cell death. J Immunol. 2006;176(12):7385-93.

12. Barile L, Vassalli G. Exosomes: therapy delivery tools and biomarkers of diseases. Pharmacol Ther. 2017:174:63-78.

13. Cheng Q, Shi X, Han M, Smbatyan G, Lenz HJ, Zhang Y. Reprogramming exosomes as nanoscale controllers of cellular immunity. J Am Chem Soc. 2018;140(48):16413-7.

14. Li W, Liu Y, Zhang P, Tang Y, Zhou M, Jiang W, et al. Tissue-engineered bone immobilized with human adipose stem cells-derived exosomes promotes bone regeneration. ACS Appl Mater Interfaces. 2018;10(6):5240-54. 
15. Zheng X, Chen F, Zhang Q, Liu Y, You P, Sun S, et al. Salivary exosomal PSMA7: a promising biomarker of inflammatory bowel disease. Protein Cell. 2017;8(9):686-95.

16. Hou J, Wang F, Liu X, Song M, Yin X. Tumor-derived exosomes enhance invasion and metastasis of salivary adenoid cystic carcinoma cells. J Oral Pathol Med. 2018;47(2):144-51.

17. Fujiwara T, Eguchi T, Sogawa C, Ono K, Murakami J, Ibaragi S, et al. Carcinogenic epithelial-mesenchymal transition initiated by oral cancer exosomes is inhibited by anti-EGFR antibody cetuximab. Oral Oncol. 2018;86:251-7.

18. Liu T, Chen G, Sun D, Lei M, Li Y, Zhou C, et al. Exosomes containing miR21 transfer the characteristic of cisplatin resistance by targeting PTEN and PDCD4 in oral squamous cell carcinoma. Acta Biochim Biophys Sin. 2017:49(9):808-16.

19. Sakha S, Muramatsu T, Ueda K, Inazawa J. Exosomal microRNA miR-1246 induces cell motility and invasion through the regulation of DENND2D in oral squamous cell carcinoma. Sci Rep. 2016;6:38750.

20. Li L, Li C, Wang S, Wang Z, Jiang J, Wang W, et al. Exosomes derived from hypoxic oral squamous cell carcinoma cells deliver miR-21 to normoxic cells to elicit a prometastatic phenotype. Cancer Res. 2016;76:1770-80.

21. Cai J, Gao N, Qiao B, Lin N. OSCC-derived exosomes promote M2-type macrophage polarization mediated by exosome-enclosed miR-29a-3p. Am J Physiol Cell Physiol. 2019;316(5):731-40.

22. Peng Q, Zhang J, Zhou G. Differentially circulating exosomal microRNAs expression profling in oral lichen planus. Am J Transl Res. 2018;10(9):2848-58.

23. Martens W, Bronckaers A, Politis C, Jacobs R, Lambrichts I. Dental stem cells and their promising role in neural regeneration: an update. Clin Oral Investig. 2013;17(9):1969-83.

24. Altanerova U, Benejova K, Altanerova V, Tyciakova S, Rychly B, Szomolanyi $\mathrm{P}$, et al. Dental pulp mesenchymal stem/stromal cells labeled with iron sucrose release exosomes and cells applied intra-nasally migrate to intracerebral glioblastoma. Neoplasma. 2016;63(6):925-33.

25. Chew JR, Chuah SJ, Teo KY, Zhang S, Lai RC, et al. Mesenchymal stem cell exosomes enhance periodontal ligament cell functions and promote periodontal regeneration. Acta Biomater. 2019;89:252-64.

26. Sjoqvist S, Ishikawa T, Shimura D, Kasai Y, Imafuku A, Bou-Ghannam S, et al. Exosomes derived from clinical-grade oral mucosal epithelial cell sheets promote wound healing. J Extracell Vesicles. 2019;8(1):1565264

27. McGough IJ, Vincent JP. Exosomes in developmental signalling. Development. 2016;143(14):2482-93.

28. Zhang Y, Yu M, Tian WD. Physiological and pathological impact of exosomes of adipose tissue. Cell Prolif. 2016;49(1):3-13.

29. Ghossoub R, Lembo F, Rubio A, Gaillard CB, Bouchet J, Vitale N, et al. Syntenin-ALIX exosome biogenesis and budding into multivesicular bodies are controlled by ARF6 and PLD2. Nat Commun. 2014;5:3477.

30. Xu AT, Lu JT, Ran ZH, Zheng Q. Exosome in intestinal mucosal immunity. J Gastroenterol Hepatol. 2016;31(10):1694-9.

31. Xie Y, Chen Y, Zhang L, Ge W, Tang P. The roles of bone-derived exosomes and exosomal microRNAs in regulating bone remodelling. J Cell Mol Med. 2016;21(5):1033-41.

32. Whiteside TL. Tumor-derived exosomes and their role in tumor-induced immune suppression. Vaccines. 2016;4:35-46.

33. Thery C, Ostrowski M, Segura E. Membrane vesicles as conveyors of immune responses. Nat Rev Immunol. 2009;9(8):581-93.

34. Yellon DM, Davidson SM. Exosomes: nanoparticles involved in cardioprotection? Circ Res. 2014;114(2):325-32.

35. Soung YH, Nguyen T, Cao H, Lee J, Chung J. Emerging roles of exosomes in cancer invasion and metastasis. BMB Rep. 2016:49(1):18-25.

36. Xiao T, Zhang W, Jiao B, Pan CZ, Liu X, Shen L. The role of exosomes in the pathogenesis of Alzheimer' disease. Transl Neurodegener. 2017;6:3.

37. Sasahira T, Kirita T. Hallmarks of cancer-related newly prognostic factors of oral squamous cell carcinoma. Int J Mol Sci. 2018;19:8.

38. Domingues C, Serambeque BP, Candido MS, Marto CMM, Veiga FJB, Ribeiro $A B$, et al. Epithelial-mesenchymal transition and microRNAs: challenges and future perspectives in oral cancer. Head Neck. 2018;40(10):2304-13.

39. Sento S, Sasabe E, Yamamoto T. Application of a persistent heparin treatment inhibits the malignant potential of oral squamous carcinoma cells induced by tumor cell-derived exosomes. PLOS ONE. 2016:11(2):e0148454.
40. Mutschelknaus L, Peters C, Winkler K, Yentrapalli R, Heider T, Atkinson MJ, et al. Exosomes derived from squamous head and neck cancer promote cell survival after ionizing radiation. PLOS ONE. 2016;11(3):e0152213.

41. Jelonek K, Wojakowska A, Marczak L, Muer A, Tinhofer-Keilholz I, Lysek-Gladysinska $M$, et al. lonizing radiation affects protein composition of exosomes secreted in vitro from head and neck squamous cell carcinoma. Acta Biochim Pol. 2015;62(2):265-72.

42. Ono K, Eguchi T, Sogawa C, Calderwood SK, Kasai T, et al. HSP-enriched properties of extracellular vesicles involve survival of metastatic oral cancer cells. J Cell Biochem. 2018;119(9):7350-62.

43. Wang Y, Qin X, Zhu X, Chen W, Zhang J, Chen W. Oral cancer-derived exosomal NAP1 enhances cytotoxicity of natural killer cells via the IRF-3 pathway. Oral Oncol. 2018;76:34-41.

44. Huang CM, Yan TL, Xu Z, Wang M, Zhou XC, Jiang EH, et al. Hypoxia enhances fusion of oral squamous carcinoma cells and epithelial cells partly via the epithelial-mesenchymal transition of epithelial cells. Biomed Res Int. 2018;2018:5015203.

45. Zhu Y, Yang J, Xu D, Gao XM, Zhang Z, Hsu JL, et al. Disruption of tumour-associated macrophage trafficking by the osteopontininduced colony-stimulating factor-1 signalling sensitises hepatocellular carcinoma to anti-PD-L1 blockade. Gut. 2019;68(9):1653-66.

46. Ye X, Zhang J, Lu R, Zhou G. Signal regulatory protein alpha associated with the progression of oral leukoplakia and oral squamous cell carcinoma regulates phenotype switch of macrophages. Oncotarget. 2016;7(49):81305-21.

47. Ye XJ, Wang XJ, Lu R, Zhang J, Chen XM, Zhou G. CD47 as a potential prognostic marker for oral leukoplakia and oral squamous cell carcinoma. Oncol Lett. 2018;15:9075-80.

48. Mori K, Hiroi M, Shimada J, Ohmori Y. Infiltration of m2 tumor-associated macrophages in oral squamous cell carcinoma correlates with tumor malignancy. Cancers (Basel). 2011;3(4):3726-39.

49. Mezawa Y, Orimo A. The roles of tumor- and metastasis-promoting carcinoma-associated fibroblasts in human carcinomas. Cell Tissue Res. 2016:365(3):675-89.

50. Attieh Y, Vignjevic DM. The hallmarks of CAFs in cancer invasion. Eur J Cell Biol. 2016;95(11):493-502

51. Shiga K, Hara M, Nagasaki T, Sato T, Takahashi H, Takeyama H. Cancerassociated fibroblasts: their characteristics and their roles in tumor growth. Cancers (Basel). 2015;7(4):2443-58.

52. Languino LR, Singh A, Prisco M, Inman GJ, Luginbuhl A, Curry JM, et al. Exosome-mediated transfer from the tumor microenvironment increases TGF $\beta$ signaling in squamous cell carcinoma. Am J Transl Res. 2016;8(5):2432-7.

53. Li Y, Tao YW, Gao S, Li P, Zheng JM, Zhang SE, et al. Cancer-associated fibroblasts contribute to oral cancer cells proliferation and metastasis via exosome-mediated paracrine miR-34a-5p. EBioMedicine. 2018;36:209-20.

54. Dourado MR, Korvala J, Astrom P, De Oliveira CE, Cervigne NK, Mofatto LS, et al. Extracellular vesicles derived from cancer-associated fibroblasts induce the migration and invasion of oral squamous cell carcinoma. J Extracell Vesicles. 2019;8(1):1578525.

55. Jiang E, Xu Z, Wang M, Yan T, Huang C, Zhou X, et al. Tumoral microvesicle-activated glycometabolic reprogramming in fibroblasts promotes the progression of oral squamous cell carcinoma. FASEB J. 2019;33(4):5690-703.

56. Zhou X, Yan T, Huang C, Xu Z, Wang L, Jiang E, et al. Melanoma cellsecreted exosomal miR-155-5p induce proangiogenic switch of cancerassociated fibroblasts via SOCS1/JAK2/STAT3 signaling pathway. J Exp Clin Cancer Res. 2018;37(1):242-56.

57. Marrugo-Ramirez J, Mir M, Samitier J. Blood-based cancer biomarkers in liquid biopsy: a promising non-invasive alternative to tissue biopsy. Int J Mol Sci. 2018;19(10):2877-97.

58. Zlotogorski-Hurvitz A, Dayan D, Chaushu G, Salo T, Vered M. Morphological and molecular features of oral fluid-derived exosomes: oral cancer patients versus healthy individuals. J Cancer Res Clin Oncol. 2016;142(1):101-10.

59. Gai C, Camussi F, Broccoletti R, Gambino A, Cabras M, Molinaro L, et al. Salivary extracellular vesicle-associated miRNAs as potential biomarkers in oral squamous cell carcinoma. BMC cancer. 2018;18(1):439-49. 
60. Winck FV, Prado Ribeiro AC, Ramos Domingues R, Ling LY, Riano-Pachon DM, Rivera C, et al. Insights into immune responses in oral cancer through proteomic analysis of saliva and salivary extracellular vesicles. Sci Rep. 2015;5:16305.

61. Zlotogorski-Hurvitz A, Dekel BZ, Malonek D, Yahalom R, Vered M. FTIRbased spectrum of salivary exosomes coupled with computationalaided discriminating analysis in the diagnosis of oral cancer. J Cancer Res Clin Oncol. 2019;145(3):685-94.

62. Ludwig S, Floros T, Theodoraki MN, Hong CS, Jackson EK, Lang S, et al. Suppression of lymphocyte functions by plasma exosomes correlates with disease activity in patients with head and neck cancer. Clin Cancer Res. 2017;23(16):4843-54.

63. Rabinowits G, Bowden M, Flores $L M$, Verselis $S$, Vergara $V$, Jo VY, et al. Comparative analysis of microRNA expression among benign and malignant tongue tissue and plasma of patients with tongue cancer. Front Oncol. 2017;7:191.

64. Theodoraki MN, Yerneni SS, Hoffmann TK, Gooding WE, Whiteside TL. Clinical significance of PD-L1(+) exosomes in plasma of head and neck cancer patients. Clin Cancer Res. 2018;24(4):896-905.

65. Wang SH, Liou GG, Liu SH, Chang JS, Hsiao JR, Yen YC, et al. Laminin gamma2-enriched extracellular vesicles of oral squamous cell carcinoma cells enhance in vitro lymphangiogenesis via integrin alpha3-dependent uptake by lymphatic endothelial cells. Int J Cancer. 2019;114(11):2795-810.

66. Speight PM, Khurram SA, Kujan O. Oral potentially malignant disorders: risk of progression to malignancy. Oral Surg Oral Med Oral Pathol Oral Radiol. 2018;125(6):612-27.

67. Altanerova U, Babincova M, Babinec P, Benejova K, Jakubechova J, Altanerova $\mathrm{V}$, et al. Human mesenchymal stem cell-derived iron oxide exosomes allow targeted ablation of tumor cells via magnetic hyperthermia. Int J Nanomed. 2017;12:7923-36.

68. Li W, Han Y, Zhao Z, Ji X, Wang X, Jin J, et al. Oral mucosal mesenchymal stem cellderived exosomes: a potential therapeutic target in oral premalignant lesions. Int J Oncol. 2019;54(5):1567-78.

69. Wang L, Yin P, Wang J, Wang Y, Sun Z, Zhou Y, et al. Delivery of mesenchymal stem cells-derived extracellular vesicles with enriched miR-185 inhibits progression of OPMD. Artif Cells Nanomed Biotechnol. 2019;47(1):2481-91.

70. Hajishengallis G. Periodontitis: from microbial immune subversion to systemic inflammation. Nat Rev Immunol. 2015;15(1):30-44.

71. Slots J. Periodontology: past, present, perspectives. Periodontol 2000. 2013;62(1):7-19.

72. Papapanou PN, Sanz M, Buduneli N, Dietrich T, Feres M, Fine DH, et al. Periodontitis: consensus report of workgroup 2 of the 2017 World Workshop on the Classification of Periodontal and Peri-Implant Diseases and Conditions. J Clin Periodontol. 2018;45(Suppl 20):S162-70.

73. Tonetti MS, Greenwell H, Kornman KS. Staging and grading of periodontitis: framework and proposal of a new classification and case definition. J Clin Periodontol. 2018;45(Suppl 20):S149-61.

74. Graves DT, Cochran D. The contribution of interleukin-1 and tumor necrosis factor to periodontal tissue destruction. J Periodontol. 2003;74(3):391-401.

75. Zhao M, Dai W, Wang H, Xue C, Feng J, He Y, Wang P, et al. Periodontal ligament fibroblasts regulate osteoblasts by exosome secretion induced by inflammatory stimuli. Arch Oral Biol. 2019;105:27-34.

76. Pavasant $P$, Yongchaitrakul T. Role of mechanical stress on the function of periodontal ligament cells. Periodontol 2000. 2011;56(1):154-65.

77. Wang Z, Maruyama K, Sakisaka Y, Suzuki S, Tada H, Suto M, et al. Cyclic stretch force induces periodontal ligament cells to secrete exosomes that suppress IL-1 $\beta$ production through the inhibition of the $\mathrm{nf}-\mathrm{kb}$ signaling pathway in macrophages. Frontiers in Immunology. 2019;10:1310.

78. Fawzy El-Sayed KM, Elahmady M, Adawi Z, Aboushadi N, Elnaggar A, Eid $M$, et al. The periodontal stem/progenitor cell inflammatory-regenerative cross talk: a new perspective. J Periodontal Res. 2019;54(2):81-94.

79. Zheng Y, Dong C, Yang J, Jin Y, Zheng W, Zhou Q, et al. Exosomal microRNA-155-5p from PDLSCs regulated Th17/Treg balance by targeting sirtuin-1 in chronic periodontitis. J Cell Physiol. 2019;234(11):20662-74.

80. Yu J, Lin Y, Xiong X, Li K, Yao Z, Dong H, et al. Detection of exosomal PD-L1 RNA in saliva of patients with periodontitis. Frontiers in genetics. 2019;10:202.
81. Tobón-Arroyave SI, Celis-Mejía N, Córdoba-Hidalgo MP, Isaza-Guzmán DM. Decreased salivary concentration of CD9 and CD81 exosomerelated tetraspanins may be associated with the periodontal clinical status. J Clin Periodontol. 2019;46(4):470-80.

82. Bowman SJ. Primary Sjögren's syndrome. Lupus. 2018;27:32-5.

83. Kroese F, Haacke EA, Bombardieri M. The role of salivary gland histopathology in primary Sjögren's syndrome: promises and pitfalls. Clin Exp Rheumatol. 2018;112(3):222-33.

84. Kyriakidis NC, Kapsogeorgou EK, Tzioufas AG. A comprehensive review of autoantibodies in primary Sjogren's syndrome: clinical phenotypes and regulatory mechanisms. J Autoimmun. 2014;51:67-74.

85. Martin-Nares E, Hernandez-Molina G. Novel autoantibodies in Sjogren's syndrome: a comprehensive review. Autoimmun Rev. 2019;18(2):192-8.

86. Kapsogeorgou EK, Abu-Helu RF, Moutsopoulos HM, Manoussakis MN. Salivary gland epithelial cell exosomes: a source of autoantigenic ribonucleoproteins. Arthritis Rheum. 2005:52(5):1517-21.

87. Aqrawi LA, Galtung HK, Vestad B, Ovstebo R, Thiede B, Rusthen S, et al. Identification of potential saliva and tear biomarkers in primary Sjogren's syndrome, utilising the extraction of extracellular vesicles and proteomics analysis. Arthritis Res Ther. 2017;19:14.

88. Lucchesi D, Pitzalis C, Bombardieri M. EBV and other viruses as triggers of tertiary lymphoid structures in primary Sjogren's syndrome. Expert Rev Clin Immunol. 2014;10(4):445-55.

89. Gallo A, Jang SI, Ong JL, Perez P, Tandon M, Ambudkar I, et al. Targeting the $\mathrm{Ca}(2+)$ Sensor STIM1 by Exosomal Transfer of Ebv-miR-BART13-3p is Associated with Sjogren's Syndrome. EBioMedicine. 2016;10:216-26.

90. Nogueira PA, Carneiro S, Ramos-e-Silva M. Oral lichen planus: an update on its pathogenesis. Int J Dermatol. 2015;54(9):1005-10.

91. Ismail SB, Kumar SK, Zain RB. Oral lichen planus and lichenoid reactions: etiopathogenesis, diagnosis, management and malignant transformation. J Oral Sci. 2007:49(2):89-106.

92. Roopashree MR, Gondhalekar RV, Shashikanth MC, George J, Thippeswamy SH, Shukla A. Pathogenesis of oral lichen planus-a review. J Oral Pathol Med. 2010;39(10):729-34.

93. Byun JS, Hong SH, Choi JK, Jung JK, Lee HJ. Diagnostic profiling of salivary exosomal microRNAs in oral lichen planus patients. Oral Dis. 2015;21(8):987-93.

94. Peng Q, Zhang J, Zhou G. Circulating exosomes regulate T-cell-mediated inflammatory response in oral lichen planus. J Oral Pathol Med. 2019:48(2):143-50.

95. Osterback R, Vuorinen T, Linna M, Susi P, Hyypia T, Waris M. Coxsackievirus A6 and hand, foot, and mouth disease. Finland. Emerg Infect Dis. 2009;15(9):1485-8.

96. Yan JJ, Su IJ, Chen PF, Liu CC, Yu CK, Wang JR. Complete genome analysis of enterovirus 71 isolated from an outbreak in Taiwan and rapid identification of enterovirus 71 and coxsackievirus A16 by RT-PCR. J Med Virol. 2001;65(2):331-9.

97. Huang CC, Liu CC, Chang YC, Chen CY, Wang ST, Yeh TF. Neurologic complications in children with enterovirus 71 infection. N Engl J Med. 1999:341(13):936-42.

98. Jia $\mathrm{HL}, \mathrm{He} \mathrm{CH}$, Wang XY, Xu YF, Yin GQ, Mao LJ, et al. MicroRNA expression profile in exosome discriminates extremely severe infections from mild infections for hand, foot and mouth disease. BMC Infect Dis. 2014;14:506.

99. Estrela C, Alencar AH, Kitten GT, Vencio EF, Gava E. Mesenchymal stem cells in the dental tissues: perspectives for tissue regeneration. Braz Dent J. 2011;22(2):91-8.

100. Martínez Sarrà E. Methodology, biology and clinical applications of mesenchymal stem cells. Front Biosci. 2009;14:4281-98.

101. Huang CC, Narayanan R, Alapati S, Ravindran S. Exosomes as biomimetic tools for stem cell differentiation: applications in dental pulp tissue regeneration. Biomaterials. 2016;111:103-15.

102. Rombouts C, Giraud T, Jeanneau C, About I. Pulp vascularization during tooth development, regeneration, and therapy. J Dent Res. 2017;96(2):137-44.

103. Xian X, Gong Q, Li C, Guo B, Jiang H. Exosomes with highly angiogenic potential for possible use in pulp regeneration. J Endod. 2018:44(5):751-8

104. Jiang N, Xiang L, He L, Yang G, Zheng J, Wang C, et al. Exosomes mediate epithelium-mesenchyme crosstalk in organ development. ACS Nano. 2017;11(8):7736-46. 
105. Li Z, Liang Y, Pan K, Li H, Yu M, Guo W, et al. Schwann cells secrete extracellular vesicles to promote and maintain the proliferation and multipotency of hDPCs. Cell Prolif. 2017;50(4):e12353.

106. Rosenberger L, Ezquer M, Lillo-Vera F, Ortuzar MI, Gonzalez PL, FigueroaValdes Al, et al. Stem cell exosomes inhibit angiogenesis and tumor growth of oral squamous cell carcinoma. Sci Rep. 2019;9(1):663-74.

107. Pivoraite $U$, Jarmalaviciute $A$, Tunaitis V, Ramanauskaite $G$, Vaitkuviene A, Kaseta $V$, et al. Exosomes from human dental pulp stem cells suppress carrageenan-induced acute inflammation in mice. Inflammation. 2015;38(5):1933-41.

108. Jarmalaviciute A, Tunaitis V, Pivoraite U, Venalis A, Pivoriunas A Exosomes from dental pulp stem cells rescue human dopaminergic neurons from 6-hydroxy-dopamine-induced apoptosis. Cytotherapy. 2015;17(7):932-9.

109. Mohammed E, Khalil E, Sabry D. Effect of adipose-derived stem cells and their exo as adjunctive therapy to nonsurgical periodontal treatment: a histologic and histomorphometric study in rats. Biomolecules. 2018;8:4.

110. Board-Davies E, Moses R, Sloan A, Stephens P, Davies LC. Oral mucosal lamina propria-progenitor cells exert antibacterial properties via the secretion of osteoprotegerin and haptoglobin. Stem Cells Transl Med. 2015;4(11):1283-93

111. Mak K, Manji A, Gallant-Behm C, Wiebe C, Hart DA, Larjava H, et al. Scarless healing of oral mucosa is characterized by faster resolution of inflammation and control of myofibroblast action compared to skin wounds in the red Duroc pig model. J Dermatol Sci. 2009;56(3):168-80.

112. Leavitt T, Hu MS, Marshall CD, Barnes LA, Lorenz HP, Longaker MT. Scarless wound healing: finding the right cells and signals. Cell Tissue Res. 2016;365(3):483-93.

113. Singh B, Mitragotri S. Harnessing cells to deliver nanoparticle drugs to treat cancer. Biotechnol Adv. 2019. https://doi.org/10.1016/j.biotechadv 2019.01.006.

114. Zhang D, Qin X, Wu T, Qiao Q, Song Q, Zhang Z. Extracellular vesicles based self-grown gold nanopopcorn for combinatorial chemo-photothermal therapy. Biomaterials. 2019;197:220-8.

115. Liao W, Du Y, Zhang C, Pan F, Yao Y, Zhang T, et al. Exosomes: the next generation of endogenous nanomaterials for advanced drug delivery and therapy. Acta Biomater. 2019;86:1-14.
116. Kim MS, Haney MJ, Zhao Y, Mahajan V, Deygen I, Klyachko NL, et al. Development of exosome-encapsulated paclitaxel to overcome MDR in cancer cells. Nanomed Nanotechnol Biol Med. 2016;12(3):655-64.

117. Barclay AN, Van den Berg TK. The interaction between signal regulatory protein alpha (SIRPalpha) and CD47: structure, function, and therapeutic target. Annu Rev Immunol. 2014;32:25-50.

118. Koh E, Lee EJ, Nam GH, Hong Y, Cho E, Yang Y, et al. Exosome-SIRPalpha, a CD47 blockade increases cancer cell phagocytosis. Biomaterials. 2017:121:121-9.

119. Robert BM, Dakshinamoorthy M, Ganapathyagraharam RB, Dhandapani $M$, Thangaiyan R, Muthusamy $G$, et al. Predicting tumor sensitivity to chemotherapeutic drugs in oral squamous cell carcinoma patients. Sci Rep. 2018;8:15545.

120. Singh A, Trivedi P, Jain NK. Advances in siRNA delivery in cancer therapy. Artif Cells Nanomed Biotechnol. 2018;46(2):274-83.

121. Shtam TA, Kovalev RA, Varfolomeeva EY, Makarov EM, Kil YV. Exosomes are natural carriers of exogenous siRNA to human cells in vitro. Cell Commun Signal. 2013;11:88-97.

122. Alvarez-Erviti L, Seow Y, Yin H, Betts C, Lakhal S, Wood MJ. Delivery of siRNA to the mouse brain by systemic injection of targeted exosomes. Nat Biotechnol. 2011;29(4):341-5.

123. Rickman K, Smogorzewska A. Advances in understanding DNA processing and protection at stalled replication forks. J Cell Biol. 2019;218(4):1096-107.

124. van der Zon NL, Kanaar R, Wyman C. Variation in RAD51 details a hub of functions: opportunities to advance cancer diagnosis and therapy. F1000Res. 2018. https://doi.org/10.12688/f1000research.15650.2.eColl ection2018.

125. Li S, Liu X, Zhou Y, Acharya A, Savkovic V, Xu C, et al. Shared genetic and epigenetic mechanisms between chronic periodontitis and oral squamous cell carcinoma. Oral Oncol. 2018;86:216-24.

\section{Publisher's Note}

Springer Nature remains neutral with regard to jurisdictional claims in published maps and institutional affiliations.

Ready to submit your research? Choose BMC and benefit from

- fast, convenient online submission

- thorough peer review by experienced researchers in your field

- rapid publication on acceptance

- support for research data, including large and complex data types

- gold Open Access which fosters wider collaboration and increased citations

- maximum visibility for your research: over 100M website views per year

At $B M C$, research is always in progress.

Learn more biomedcentral.com/submissions 